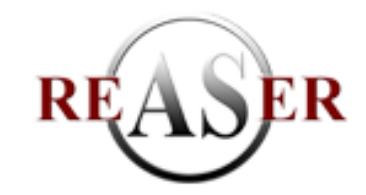

ISSN: 2247-6172;

ISSN-L: 2247-6172

Review of Applied Socio- Economic Research

(Volume 5, Issue 1/ 2013 ), pp. 179

URL: http://www.reaser.eu

e-mail: editors@reaser.eu

\title{
Global macroeconomic interdependence: a minimum spanning tree approach
}

\author{
Tiago Trancoso ${ }^{1+}$ \\ ${ }^{1}$ Lusíada University and Instituto Politécnico de Viana do Castelo
}

\begin{abstract}
This paper measures the evolution of the interdependence level of the global economic system using a novel approach that combines network analysis and time-varying correlations. A Scalar-BEKK model is employed to determine the dynamic conditional bilateral correlations of 102 economies for the period 1952-2011. A subdominant ultrametric space is then defined for each year by applying a single-link cluster analysis to filter and highlight first-order connections in the network. I find the core of the global economic network to be dominated by advanced economies while the periphery is composed by nearly all of the developing economies and some of the emergent market economies; France occupies the central hub of the network, which coincides with recent findings from studies on European financial markets. I also find that the global macroeconomic interdependence rose over 61\% between 1952-2011, which is in line with the majority of the empirical research on business cycle synchronization; however, this paper reveals an accelerating convergence process during the phase 1996-2011 that exceeds results from previous studies.
\end{abstract}

Keywords: macroeconomic interdependence; global convergence; international business cycles; network analysis; dynamic correlations.

JEL codes: C38; F41; F44; O47.

\section{Introduction}

A significant part of the studies on international business cycles presents evidence for the existence of a process of increasing synchronization of business cycles (Lumsdaine and Prasad 2003, Bordo and Helbling 2004, Artis et al. 2011). The record high levels of global synchrony in the first decade of 21st century, at levels at least not seen since world war II, is a phenomenon also observed by several studies that apply different approaches and methodologies (Kuzin and Hillebrand 2009, Banerji and Dua 2010, Gomez et al. 2011, Antonakakis 2012, Antonakakis and Scharler 2012).

Following this framework, a body of recent research argues that overall level of comovement between economies has reached sufficient magnitude to consider the emergence of a global economic cycle. Most of this work uses dynamic factor models for comparing the relative importance of the global common factor vis-a-vis the idiosyncratic factors specific to each economy. Accordingly, some studies adopt the activity level of the G-7 as a measure for the global economic cycle, concluding that the global factor explains most of the covariation between countries as well as the global cyclical events noted during the most recent period of globalization (Lumsdaine and Prasad 2003, Canova et al. 2007). Considering the correlations between the G-7 economies, the permanent component appears to explain a significant portion of their respective GDP fluctuations (Moneta and Rüffer 2009), productivity (Glick and Rogoff 1995), consumption (Ayhan Kose et al. 2008), investment (Gregory and Head 1999) and terms of trade (Crucini et al. 2011). However, this perspective of convergence between national business cycles, especially from the beginning of the 21 st

+ Corresponding author. E-mail address: tiagotrancoso@gmail.com. 


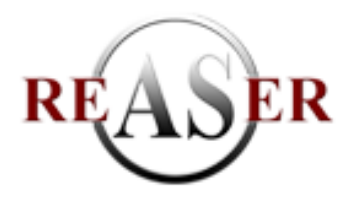

ISSN: 2247-6172;

ISSN-L: 2247-6172

Review of Applied Socio- Economic Research

(Volume 5, Issue 1/ 2013 ), pp. 180

URL: http://www.reaser.eu

e-mail: editors@reaser.eu

century onwards, is not consensual. Miśkiewicz and Ausloos (2010) study the process of globalization of the world economy, supporting their analysis on a measure of entropy they conclude that the process has reached a peak in the period 1970-2000, then followed by a process of de-globalization. Other studies show that levels of correlation across countries are positive but not very high (Ambler et al. 2004) or do not show a clear trend of growth (Doyle and Faust 2005).

The aforementioned studies focus almost exclusively on samples comprised of advanced economies (G$7 / \mathrm{OECD} / \mathrm{EU})$. Is it possible to represent the comprehensive global economic network and to measure its level of interdependence? In order to address this question, the paper proposes a wide novel approach which combines network analysis with time-varying bilateral correlations between 102 economies for the period 1952-2011. A Scalar-BEKK model is employed to determine the dynamic conditional correlations for each year and then a single-link cluster analysis is applied to filter and highlight the first-order connections in the global economic network. Section 2 derives the dynamic conditional correlations model and the subdominant ultrametric space resultant from the network filtering procedure. Section 3 analyses the mean network topology and its structural evolution from 1952 to 2011; 3 distinct phases are found in the network structural evolution: 1952-1973, 1974-1995 and 1996-2011. Section 4 defines the interdependence measures based on topological distances and examines the evolution of the global economic network over the period 1952-2011. Section 5 summarizes the main findings and suggests further topics for research.

\section{Methodological approach}

\subsection{Dynamic Conditional Correlations}

A dynamic conditional correlation model is employed to obtain a time-varying measure of bilateral business cycle correlations between 102 economies from 1952 until 2011. Since the late 1980's, many new models and empirical applications of dynamic covariance models and dynamic correlation models emerged, based on multivariate Generalized Autoregressive Conditional Heteroskedascity (GARCH) processes.

Consider a $m * 1$ vector stochastic process of annual growth rates and condition on the information set at time $t-1$ :

$$
\begin{gathered}
y_{t}=E\left(y_{t} \mid I_{t-1}\right)+\varepsilon_{t} \\
\varepsilon_{t}=D_{t} \eta_{t}
\end{gathered}
$$

$E\left(y_{t} \mid I_{t-1}\right)$ represents the conditional mean, $D_{t}=\operatorname{diag}\left(h_{1 t}, h_{2 t}, \ldots, h_{m t}\right)$ with $h_{i t}=E\left(\varepsilon_{i t}^{2} \mid I_{t-1}\right)$ and $\eta_{t}$ is a random vector assuming to follow $E\left(\eta_{t}\right)=0$ and $\operatorname{Var}\left(\eta_{t}\right)=I_{M}$, where $I_{m}$ is the identity matrix of order M.Let $H_{t}=E\left(\varepsilon_{t} \varepsilon_{t}^{\prime} \mid I_{t-1}\right)$ be the conditional covariances matrix, which can also be represented by:

$$
H_{t}=D_{t} R_{t} D_{t}
$$

where $R_{t}=E\left(\eta_{t} \eta_{t}^{\prime} \mid I_{t-1}\right)$ is the matrix of conditional correlations.

The BEKK model proposed by Engle and Kroner (1995) defines the conditional covariance matrix as:

$$
H_{t}=C C^{\prime}+\sum_{k=1}^{K} A_{k}^{\prime} \varepsilon_{t-1} \varepsilon_{t-1}^{\prime} A_{k}+\sum_{k=1}^{K} B_{k}^{\prime} H_{t-1} B_{k}
$$

where $C, A_{k}$ and $B_{k}$ are square coefficient matrices and $H_{t-1}$ is a triangular coefficient matrix. Engle and Kroner (1995) provide sufficient conditions to identify BEKK models with $K=1$, namely that $A_{k, 11}, B_{k, 11}$ and diagonal elements of $\mathrm{C}$ are restricted to be positive and I follow this specification. The conditional correlation matrix can be indirectly obtained from (3) as follows:

$$
R_{t}=D_{t}^{-1} H_{t} D_{t}^{-1}
$$

Considering $K=1$ and substituting (4) into (5), a final expression is derived for the conditional correlation matrix: 


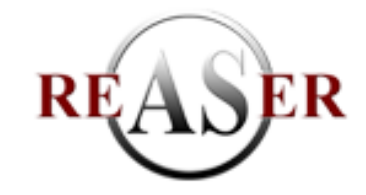

ISSN: 2247-6172;

ISSN-L: 2247-6172

Review of Applied Socio- Economic Research

(Volume 5, Issue 1/ 2013 ), pp. 181

URL: http://www.reaser.eu

e-mail: editors@reaser.eu

$$
R_{t}=\left(D_{t}^{-1} C\right)\left(D_{t}^{-1} C\right)^{\prime}+\left(D_{t}^{-1} A \varepsilon_{t-1}\right)\left(D_{t}^{-1} A \varepsilon_{t-1}\right)^{\prime}+\left(D_{t}^{-1} B H_{t-1}^{1 / 2}\right)\left(D_{t}^{-1} B H_{t-1}^{1 / 2}\right)^{\prime}
$$

The number of parameters in this BEKK model is $M(5 M+1) / 2$. In order to reduce the number of parameters I elaborate a Scalar-BEKK Model as in Ding and Engle (2001), considering $A=\alpha \iota^{\prime}$ and $B=\beta \iota^{\prime}$, where $\alpha$ and $\beta$ are scalars and $\iota$ is a vector of ones.

Caporin and McAleer (2008) show that the conditional correlation matrix expressed in (6) has explicit regularity conditions and asymptotic properties for the Quasi-Maximum Likelihood Estimates (QMLE) in the absence of multivariate normality of the vector of standardized residuals. Following their empirical approach, a VAR(1) model was fitted to the growth rates to compute the mean residuals. With the conditional mean given as $E\left(\varepsilon_{t} \mid I_{t-1}\right)=0$ and the conditional variance given as $E\left(\varepsilon_{t} \varepsilon_{t}^{\prime} \mid I_{t-1}\right)=\Sigma_{t}$, the model becomes:

$$
\begin{aligned}
& \Sigma_{t}=(1-\alpha-\beta) \Sigma+\alpha \varepsilon_{t-1} \varepsilon_{t-1}^{\prime}+\beta \Sigma_{t-1}, \\
& \Sigma=T^{-1} \sum_{i=1}^{T} \varepsilon_{t} \varepsilon_{t}^{\prime} .
\end{aligned}
$$

The dynamic conditional correlations are then given by:

$$
\begin{aligned}
\widetilde{\mathrm{R}}_{t} & =\bar{\Sigma}_{t}^{-1} \Sigma_{t} \bar{\Sigma}_{t}^{-1}, \\
\bar{\Sigma}_{t} & =\operatorname{diag}\left(\sigma_{11, t}, \sigma_{22, t}, \ldots, \sigma_{m m, t}\right) .
\end{aligned}
$$

and finally I apply the equations to the bivariate case.

\subsection{Subdominant ultrametric space: the minimum spanning tree approach}

The bivariate dynamic conditional correlations cannot be used as metric distances as there can be cases of negative correlation between economies (negative coefficients). However, as proved by Mantegna (1999), a metric distance can be determined from a nonlinear transformation of the correlation coefficient. I follow this approach and set:

$$
d_{i j}=\sqrt{2\left(1-\rho_{i j}\right)}
$$

where $\rho_{i j}$ means the correlation coefficient of economies $i$ and $j$. A topological space can therefore be defined, as $d_{i j}$ fulfils the three axioms of a metric distance ${ }^{1}$.

A distance matrix is then built for each period, representing a fully connected graph with edge weights $d_{i j}$. With $N$ economies the number of links in the network becomes $N(N-1) / 2$. I follow a clustering procedure known as single-linkage clustering analysis (SLCA) that provides a pruned representation of the network. This representation, named Minimum Spanning Tree (MST), allows us to represent the subdominant ultrametric space at each period. The MST is a graph that contains $N$ nodes (economies) connected by $N-1$ links such that the sum $\sum_{d_{i j} \in \mathbf{T}} d_{i j}$ is a minimum.

The MST has the advantage of reducing the complexity of the distance matrix network by showing only the $N-1$ most important non-redundant connections (first-level connections). Its dynamic application is particularly suitable for extracting the most important information when a large number of time series are under examination (Coelho et al. 2007) and relevant for complex systems containing $N$ stochastic processes whose interaction evolve over time (McDonald et al. 2005). I chose to apply SLCA because it maintains the relevant information from the correlation matrix (Coelho et al. 2007), it presents robustness of results (Onnela et al. 2003) and proves to have more stability when compared to other methods (Tumminello et al. 2010).

\footnotetext{
${ }^{1}$ Axioms: (i) $d(i, j)=0$ if and only if $i=j$; (ii) $d(i, j)=d(j, i)$; (iii) $d(i, j) \leq d(i, k)+d(k, j)$.
} 


\section{Network topology and structural dynamics (1952-2011)}

The minimum spanning tree approach is based in the conditional correlation matrix, focusing on the correlation patterns of interactions between economies. Interactions combinations result in graphs with different degrees of complexity, constructed by iteratively linking the most strongly connected economies (nodes). In this section I firstly present a static representation of the average structure of the network over the period and then I examine its stability and robustness dynamics.

Figure 1 displays a graphical representation of the minimum spanning tree generated by the mean distance between economies over the period 1952-2011. Economies (nodes) are organized according to their current development level. I follow International Monetary Fund classification procedure, distinguishing between advanced economies (red circles), emergent market economies (blue squares) and developing economies (yellow triangles). Link's thickness inversely depicts the distance between 2 economies, i.e. the thicker link represents the closest countries (smallest geodesic distance) in the tree, Germany and Austria.

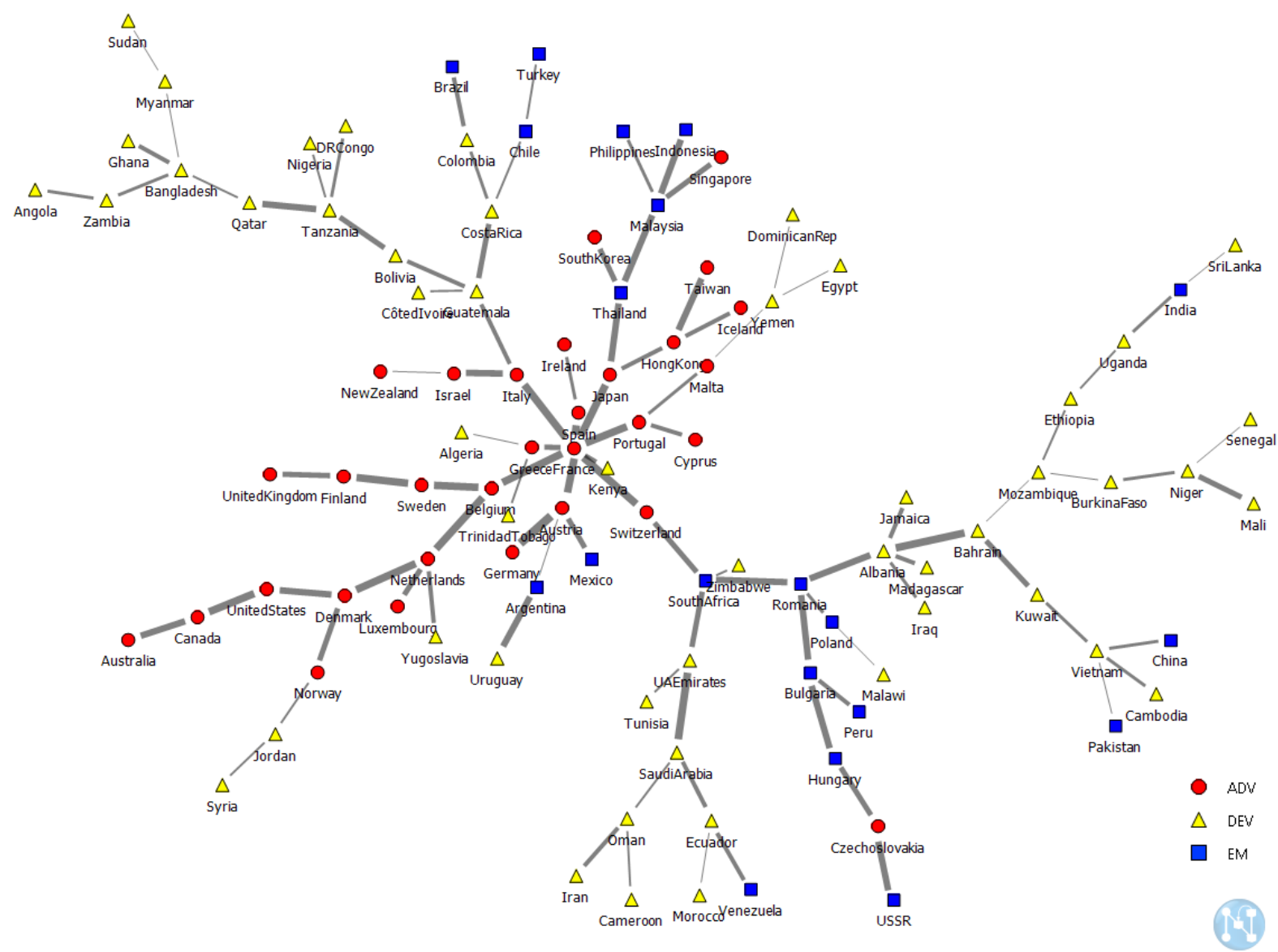

Fig.1: Global Economic Network MST (Avg. 1952-2011)

The tree provides a visual overview of the structure of interconnections. Economies tend to cluster according to development level, meaning that the majority of the first-level connections are intra-group. In fact, $73.3 \%$ of total links are between economies which share the same development degree, with the two 


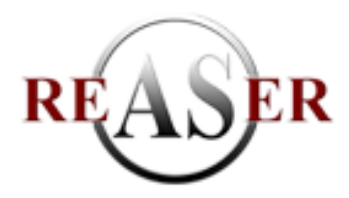

ISSN: 2247-6172;

ISSN-L: 2247-6172

Review of Applied Socio- Economic Research

(Volume 5, Issue 1/ 2013 ), pp. 183

URL: http://www.reaser.eu

e-mail: editors@reaser.eu

greatest groups being composed of developing economies (37.6\% of total links) and advanced economies $(26.7 \%$ of total links).

The stronger connections, associated to smaller distances (thicker lines in the graph), are particularly revealed inside the group formed by advanced economies; as an example, it is observable that the 10 smallest distances are between advanced economies. The advanced economies group occupies a strong compact and centralized position in the tree, connecting through direct paths ${ }^{2}$ more than $90 \%$ of all advanced economies. The tree is composed by other 5 major branches, 2 of which are mainly composed by emergent economies and the remainder are formed by developing economies. Interestingly, emergent economies tend to cluster predominantly according to geographical position, entering the tree either as a leaf (last peripheral node in the branch), as in the case of China, Brazil, Pakistan, or through the formation of geographical branches. One such branch is formed by Southeast Asian countries that connect to the advanced economies through Japan. The other branch is mainly composed of former soviet-aligned economies, connecting USSR (the leaf) to the advanced economies through Switzerland.

Next the centrality of the network structure is examined, based on pair-dependency among its nodes. This matter is relevant because a network structure with a higher level of interdependence would make the network more sensible to variations in business cycles of more central economies. In order to find how important an economy (node) is in terms of connecting other economies (nodes), I apply a network measure named node betweenness centrality and define it as it was first proposed by Freeman (1977):

$$
B_{i}=\sum_{k \neq j} \frac{P_{i}(k j) / P(k j)}{(n-1)(n-2) / 2}
$$

where $P_{i}(k j)$ denote the number of geodesic paths between $k$ and $j$ that $i$ lies on, and $P(k j)$ is the total number of geodesic paths between $k$ and $j^{3}$. The results are mapped according to a concentric algorithm and displayed in figure 2. France takes up a central role in the network, being directly and strongly connected to 9 countries and assuming a central position in all major branches. Interestingly, this result is in line with a recent body of research on financial markets ${ }^{4}$ that point France, not Germany nor United Kingdom, as the central hub of European bond and equity markets.

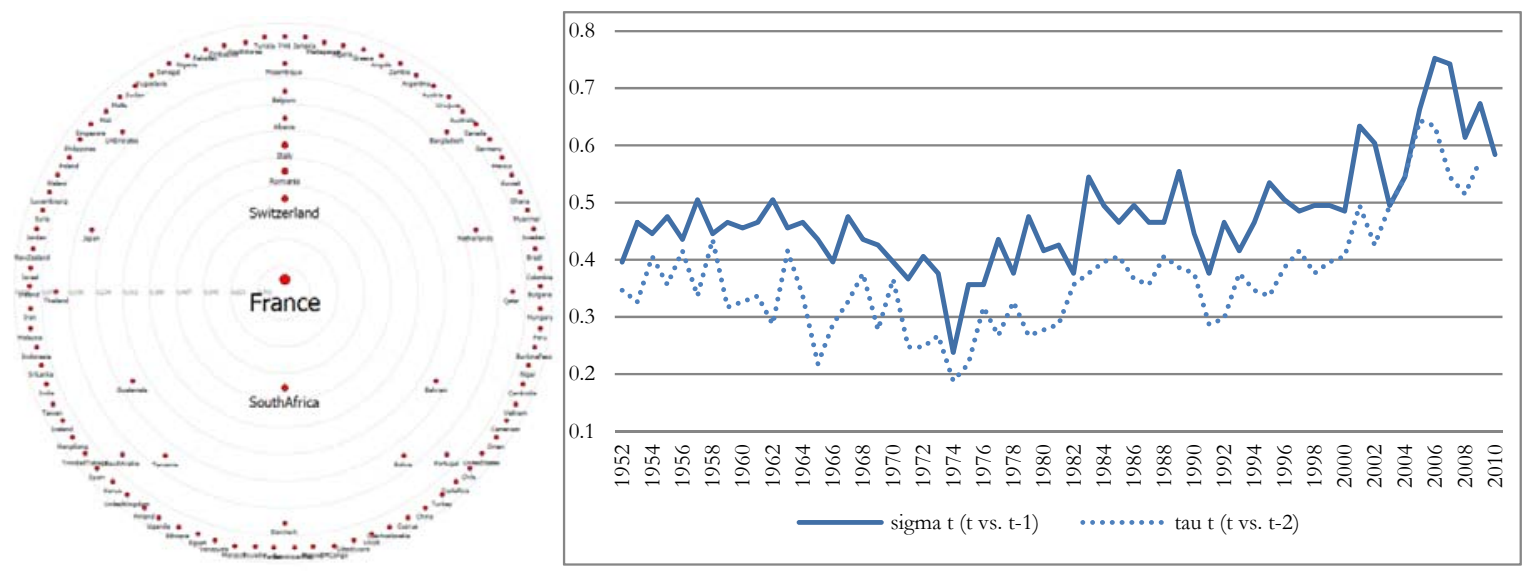

Fig. 2 - Left: Node betweenness centrality; Right: MST Survival Ratios.

\footnotetext{
${ }^{2}$ A path in Thetween nodes $i$ and $j$ is a sequence of links $i_{1} i_{2}, \ldots, i_{K-1} i_{K}$ such that $i_{k} i_{k+1} \in \boldsymbol{T}$ for each $k \in\{1, \ldots, K-1\}$, with $i_{1}=i$ and $i_{K}=j$, and such that each node in the sequence $i_{1}, \ldots, i_{K}$ is distinct (Jackson 2008).

${ }^{3} B_{i}$ is determined for every $k \neq j$ such that $i$ is not an element of $\{k, j\}$.

${ }^{4}$ For example, see: Gilmore et al. (2008), Eryigit and Eryigit (2009), Gilmore et al. (2010), Leonidas (2012).
} 


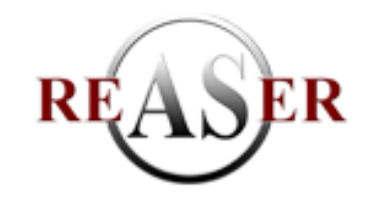

ISSN: 2247-6172;

ISSN-L: 2247-6172

Review of Applied Socio- Economic Research

(Volume 5, Issue 1/ 2013 ), pp. 184

URL: http://www.reaser.eu

e-mail: editors@reaser.eu

Time-varying correlations allow us to examine the dynamics of the network structure during the period 1952-2011. The robustness of global economic tree topology can be analysed through the concept of singlestep survival ratio, defined as the fraction of links found common in two trees (Onnela et al. 2003). The survival ratios found between year $t$ and previous years $t-1$ and $t-2$ are defined as follows:

$$
\begin{aligned}
& \sigma_{t}=\frac{1}{N-1}\left|E^{t} \cap E^{t-1}\right| \\
& \tau_{t}=\frac{1}{N-1}\left|E^{t} \cap E^{t-2}\right|
\end{aligned}
$$

where $E^{t}$ refers to the set of edges of the tree at year $t, \cap$ is the intersection operator and $|\ldots|$ gives the number of elements in the set. The stability of the tree over time is depicted in Fig. 7. In the 1970's the tree passed through a deep restructuring process, with an average ratio of $60 \%$ new links every year. Since then, network stability kept reinforcing over time, achieving a maximum survival ratio of over $75 \%$ of total links in 2007, just before the onset of the Global Recession of 2007-09.

In order to acknowledge the existence of trend breakpoints in the tree structure, I propose a simple model that regresses $\sigma_{t}$ on $\tau_{t}$ and search for breaks in equation parameters. The following OLS regression is defined:

$$
\sigma_{t}=\beta_{0}+\beta_{1} \tau_{t}+\varepsilon_{t}
$$

As expected, tree robustness dynamics demonstrated strong consistency over consecutive periods $\left(\beta_{1}=0.81\right)$. A Quandt-Andrews unknown breakpoint test ${ }^{5}$ was then performed to examine the parameters stability. The null hypothesis of no breakpoints within $15 \%$ trimmed data was rejected with $94 \%$ probability for $\tau_{t}$ and $91 \%$ probability for all equation variables ${ }^{6}$. The test results point two structural changes in MST, occurring in 1974 (for $\tau_{t}$ ) and 1996 (for all regressors). Thus these findings suggest three distinct phases in the evolution of the global economic network: 1952-1973, 1974-1995 and 1996-2011, which properties are investigated in the next section.

\section{An increasingly interdependent economic world?}

This paper proposes network distance-based measures to evaluate the level of interdependence between economies. As stated in section 2.2, for each period a bilateral distance matrix was obtained from a nonlinear transformation of the respective correlation conditional matrix. A shorter (greater) distance between two economies that are directly connected in the network correspond to a higher (lower) correlation between them. In this sense, four measures based on geodesic distances are proposed to characterize the level of interdependence observed in the network: (i) normalized tree length, (ii) average weighted degree, (iii) mean distance, and (iv) tree diameter.

The normalized tree length (NTL) measures the temporal state of the economic network and is defined as the following:

$$
L(t)=\frac{1}{N-1} \sum_{d_{i j}^{t} \in \mathbf{T}^{t}} d_{i j}^{t}
$$

where $t$ denotes time at which the tree is constructed. A representation of this measure as a function of time is depicted in figure 3 (right) and it shows that it is highly anticorrelated with mean bilateral conditional correlation plotted in figure 3 (left). The Pearson's linear coefficient between the two series is 0.815 , and it provides evidence that even though the MST is a reduced indirect representation of the correlation matrix, it retains the salient features of the global economic network.

\footnotetext{
${ }^{5}$ As developed by (Andrews 1993).

${ }^{6}$ According to corresponding Supreme likelihood ratio test statistics, probabilities computed using (Hansen 1997) method.
} 


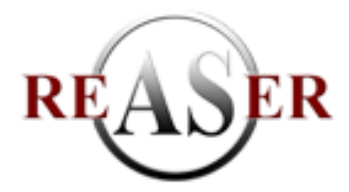

ISSN: 2247-6172;

ISSN-L: 2247-6172

Review of Applied Socio- Economic Research

(Volume 5, Issue 1/ 2013 ), pp. 185

URL: http://www.reaser.eu

e-mail: editors@reaser.eu

Figure 3 (right) shows a downward trend in the mean bilateral geodesic distance for the period 19522011 with a steep decrease since the beginning of the $21^{\text {st }}$ century. The global economic network has become much more compact and interdependent in recent years. In fact, in 2000's NTL fell to levels 66\% lower than in beginning of the 1950's and 35\% lower than previous bottoms of 1976 and 1993. Placing the remarkable downfall from 1996 to 2011 in perspective, if the network were to keep its average NTL compressing pace of $1998-2010$ (61\% increase), the global economic network would find itself in complete full synchronization (zero geodesic distance) by 2029.

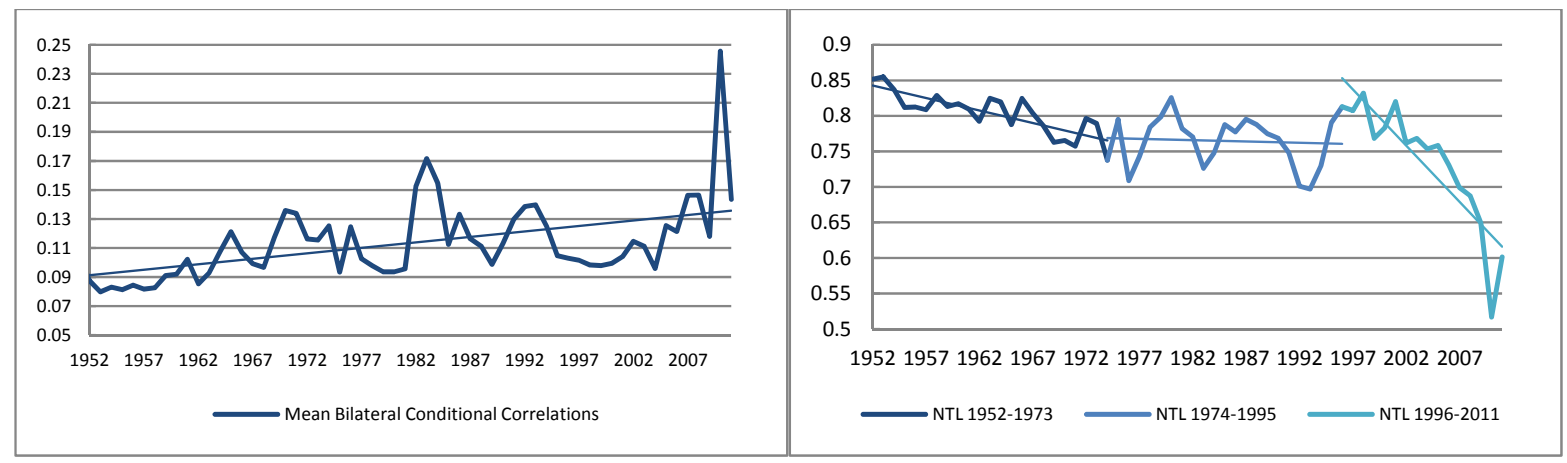

Fig. 3 - Left: mean bilateral conditional correlation; Right: normalized tree length (NTL)

A related measure can be obtained from the dynamic analysis of the tree average weighted degree. The degree of a node is the number of links that involve that node, which is the cardinality of $i$ 's neighbourhood. Degree has generally been extended to the sum of weights when analysing weighted networks and labelled node strength (Barrat et al. 2004, Newman 2004). I formalize this measure for the complete tree, name it Average Weighted Degree (AWD) and define it as follows:

$$
W(t)=N^{-1} \sum_{i}^{N} \sum_{j}^{N} d_{i j}^{t}, \quad d_{i j}^{t} \in \mathbf{T}^{t}
$$

The result for each period $t$ is depicted in fig.4. This measure is an average of weighted degrees for all the nodes of the tree, which is subject to a fixed composition of $N-1$ links. Thus an increase (decrease) in AWD should reflect a higher (lower) degree of centrality of the network, meaning if nodes are more connected to some central node(s) (higher centrality) or whether are more dispersed over the network (lower centrality). Taking this into consideration, the results (fig. 4) suggest the emergence of a process of decentralization during the first phase (1952-1973), followed by a consolidation phase (1974-1995) and then a second wave of decentralization (1996-2011).

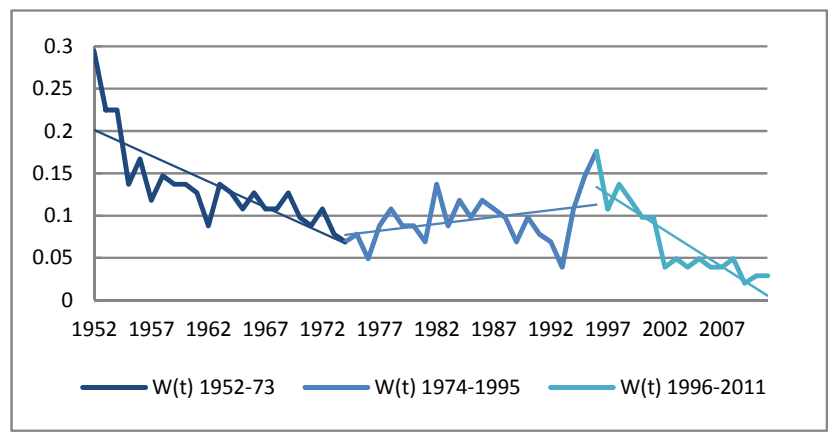

Fig. 4: MST Average Weighted Degree (W)

In a tree representation, nodes are usually connected directly to only a few nodes (at least one) while remaining indirectly connected to all the others. In order to understand how the indirect connections between 


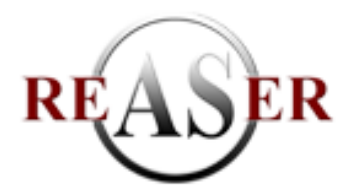

ISSN: 2247-6172;

ISSN-L: 2247-6172

Review of Applied Socio- Economic Research

(Volume 5, Issue 1/ 2013 ), pp. 186

URL: http://www.reaser.eu

e-mail: editors@reaser.eu

the economies (nodes) evolved over time in the tree, we introduce two additional distance measures: Mean Distance and Network Diameter. Distance between two nodes is the length of number of links in the shortest path or geodesic between them. Thus Mean Distance is defined as the average geodesic distance between any pair of nodes and Network Diameter as the largest geodesic distance between any pair of nodes in a network. The evolution of both distances is depicted in figure 5 .

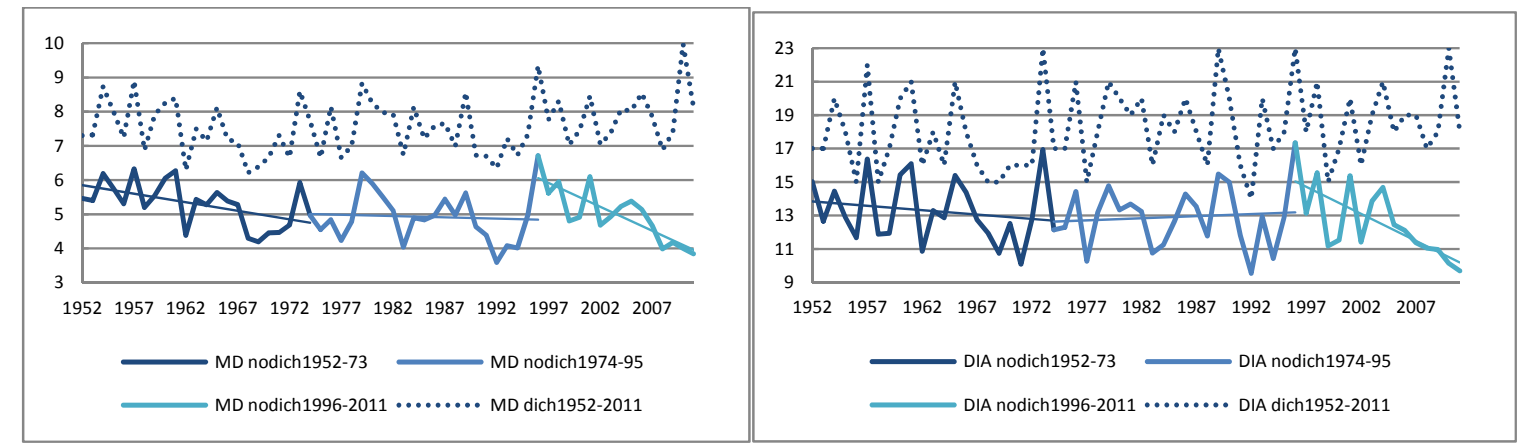

Fig. 5 - Left: Mean Distance; Right: Network diameter

It is straightforward that even though these series display greater bounded volatility than NTL and AWD. This derives from the interplay of three effects: the constraint upon tree formation, subject to $N-1$ links; the evolution of link average length (as displayed in fig 3 - right); and tree centrality. The measures are presented in both figures with and without dichotomizing the links, i.e. with and without weighting for the distances between the nodes. For example, in 2010 the mean distance between any pair of nodes was below 4 , even though in that year the average path between any pair of links rose almost to 10 links. In essence, the slight downward trend observed in both indicators was motivated by the sharp decline in NTL between 1998 and 2010, even though in this period the tree has become less centralized.

These results suggest that a simple and comprehensive measure for the level of interdependence would be to define it as the inverse of NTL. Following this perspective, this paper shows that network interdependence has increased consistently in the phase 1952-1973, reaching a local maximum (NTL minimum) in 1976, and accelerated remarkably in the phase 1996-2011, increasing over $61 \%$ between 1998 and 2010 and reaching a global maximum (NTL minimum) in 2010. These results stand in line with the vast majority of empirical studies on international business cycles synchronization, which reports a secular trend towards synchronization (Artis et al. 2011, Bordo and Helbling 2011, Antonakakis 2012). This paper findings also support the view of an unprecedented level of synchronicity between major economies during the great recession of 2007-2009, as shown by Banerji and Dua (2010), Imbs (2010) and Kuzin and Hillebrand (2009), although I present evidence that this process is broader in time (1998-2010) and in depth, as NTL drop from 0.83 in 1998 to 0.53 positioned the world $1 / 3$ closer to complete economic synchronization (zero geodesic distance).

\section{Conclusion}

This paper shows that global macroeconomic interdependence rose over $61 \%$ during the period 1952 2011, which is in line with the majority of empirical research on business cycle synchronization. However, an accelerating convergence process is revealed during the phase 1996-2011 that exceeds results from previous studies.

I find the core of the global economic network to be dominated by advanced economies while the periphery is composed by nearly all of the developing economies and some of the emergent market economies. Emergent economies tend to cluster predominantly according to geographical position, entering 


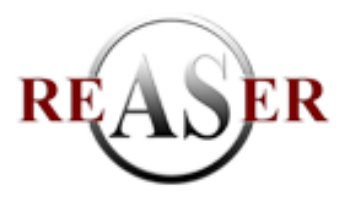

ISSN: 2247-6172;

ISSN-L: 2247-6172

Review of Applied Socio- Economic Research

(Volume 5, Issue 1/ 2013 ), pp. 187

URL: http://www.reaser.eu

e-mail: editors@reaser.eu

the tree either as a leaf or through the formation of two geographical branches: Southeast Asia and ex-soviet economies. France occupies the central hub of the network, which coincides with recent findings from research on European financial markets.

A number of topics for further research can be suggested by this paper. One is to examine the evolution of interconnections in the network according to the level of development, by examining the empirical evidence supporting the "decoupling hypothesis", meaning the claim that emergent market economies could have diverged from advanced economies during the recent period of globalization. Other topics include researching the determinants of business cycle interdependence and studying the network's local properties and its relation to local and regional economic growth.

\section{Acknowledgements}

I thank my dissertation advisor, Gonçalo Faria, Pedro Trancoso and Sofia Gomes for helpful comments on an earlier draft of this paper.

\section{References}

[1] Ambler, S., E. Cardia and C. Zimmermann, International business cycles: What are the facts?, Journal of Monetary Economics, 51 (2004), pp. 257-276.

[2] Andrews, D. W., Tests for parameter instability and structural change with unknown change point, Econometrica: Journal of the Econometric Society (1993), pp. 821-856.

[3] Angus, M., Development Centre Studies The World Economy Historical Statistics: Historical Statistics, OECD Publishing, 2003.

[4] Antonakakis, N., Business Cycle Synchronization During US Recessions Since the Beginning of the 1870s, Economics Letters, 117 (2012), pp. 467-472.

[5] Antonakakis, N. and J. Scharler, The synchronization of GDP growth in the G7 during US recessions, Applied Economics Letters, 19 (2012), pp. 7-11.

[6] Artis, M., G. Chouliarakis and P. Harischandra, Business Cycle Synchronization Since 1880, The Manchester School, 79 (2011), pp. 173-207.

[7] Ayhan Kose, M., C. Otrok and C. H. Whiteman, Understanding the evolution of world business cycles, Journal of International Economics, 75 (2008), pp. 110-130.

[8] Banerji, A. and P. Dua, Synchronisation of Recessions in Major Developed and Emerging Economies, Margin: The Journal of Applied Economic Research, 4 (2010), pp. 197-223.

[9] Barrat, A., M. Barthelemy, R. Pastor-Satorras and A. Vespignani, The architecture of complex weighted networks, Proceedings of the National Academy of Sciences of the United States of America, 101 (2004), pp. 3747-3752.

[10] Bordo, M. and T. Helbling, International Business Cycle Synchronization in Historical Perspective, The Manchester School, 79 (2011), pp. 208-238.

[11] Bordo, M. D. and T. F. Helbling, Have National Business Cycles Become More Synchronized?, Macroeconomic policies in the world economy (2004), pp. 3.

[12] Canova, F., M. Ciccarelli and E. Ortega, Similarities and convergence in G-7 cycles, Journal of Monetary Economics, 54 (2007), pp. 850-878.

[13] Caporin, M. and M. Mcaleer, Scalar BEKK and indirect DCC, Journal of Forecasting, 27 (2008), pp. 537-549.

[14] Coelho, R., C. G. Gilmore, B. Lucey, P. Richmond and S. Hutzler, The evolution of interdependence in world equity markets-Evidence from minimum spanning trees, Physica A: Statistical Mechanics and its Applications, 376 (2007), pp. 455-466.

[15] Crucini, M. J., M. A. Kose and C. Otrok, What are the driving forces of international business cycles?, Review of Economic Dynamics, 14 (2011), pp. 156-175.

[16] Ding, Z. and R. F. Engle, Large Scale Conditional Covariance Matrix Modeling, Estimation and Testing, Academia Economic Papers, 29 (2001), pp. 157-184.

[17] Doyle, B. M. and J. Faust, Breaks in the variability and comovement of G-7 economic growth, Review of Economics and Statistics, 87 (2005), pp. 721-740.

[18] Engle, R. F. and K. F. Kroner, Multivariate simultaneous generalized ARCH, Econometric theory, 11 (1995), pp. $122-150$. 


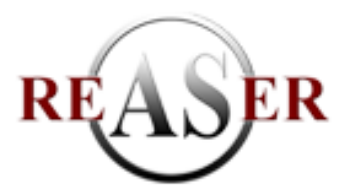

ISSN: 2247-6172;

ISSN-L: 2247-6172

Review of Applied Socio- Economic Research

(Volume 5, Issue 1/ 2013 ), pp. 188

URL: http://www.reaser.eu

e-mail: editors@reaser.eu

[19] Eryigit, M. and R. Eryigit, Network structure of cross-correlations among the world market indices, Physica A: Statistical Mechanics and its Applications, 388 (2009), pp. 3551-3562.

[20] Freeman, L. C., A set of measures of centrality based on betweenness, Sociometry (1977), pp. 35-41.

[21] Gilmore, C. G., B. M. Lucey and M. Boscia, An ever-closer union? Examining the evolution of linkages of European equity markets via minimum spanning trees, Physica A: Statistical Mechanics and its Applications, 387 (2008), pp. 6319-6329.

[22] Gilmore, C. G., B. M. Lucey and M. W. Boscia, Comovements in government bond markets: A minimum spanning tree analysis, Physica A: Statistical Mechanics and its Applications, 389 (2010), pp. 4875-4886.

[23] Glick, R. and K. Rogoff, Global versus country-specific productivity shocks and the current account, Journal of Monetary Economics, 35 (1995), pp. 159-192.

[24] Gomez, D. M., G. J. Ortega and B. Torgler, Measuring globalization: A hierarchical network approach, Center for Research in Economics, Management and the Arts (CREMA), 2011.

[25] Gregory, A. W. and A. C. Head, Common and country-specific fluctuations in productivity, investment, and the current account, Journal of Monetary Economics, 44 (1999), pp. 423-451.

[26] Hansen, B. E., Approximate Asymptotic P Values for StructuraS-Change Tests, Journal of Business \& Economic Statistics, 15 (1997), pp. 60-67.

[27] Imbs, J., The first global recession in decades, IMF economic review, 58 (2010), pp. 327-354.

[28] Jackson, M. O., Social and economic networks, Princeton Univ Pr, 2008.

[29] Kuzin, V. and M. Hillebrand, Global Business Cycles: Degree of Synchronization in the Current Downturn Is Unprecedented, Weekly Report (2009), pp. 188-192.

[30] Leonidas, S., Pruning a minimum spanning tree, Physica A: Statistical Mechanics and its Applications, 391 (2012), pp. 2678-2711.

[31] Lumsdaine, R. L. and E. S. Prasad, Identifying the Common Component of International Economic Fluctuations: A New Approach*, The Economic Journal, 113 (2003), pp. 101-127.

[32] Mantegna, R. N., Hierarchical structure in financial markets, The European Physical Journal B-Condensed Matter and Complex Systems, 11 (1999), pp. 193-197.

[33] Mcdonald, M., O. Suleman, S. Williams, S. Howison and N. F. Johnson, Detecting a currency's dominance or dependence using foreign exchange network trees, Physical Review E, 72 (2005), pp. 046106.

[34] Miśkiewicz, J. and M. Ausloos, Has the world economy reached its globalization limit?, Physica A: Statistical Mechanics and its Applications, 389 (2010), pp. 797-806.

[35] Moneta, F. and R. Rüffer, Business cycle synchronisation in East Asia, Journal of Asian Economics, 20 (2009), pp. $1-12$.

[36] Newman, M. E., Analysis of weighted networks, Physical Review E, 70 (2004), pp. 056131.

[37] Onnela, J. P., A. Chakraborti, K. Kaski, J. Kertesz and A. Kanto, Dynamics of market correlations: Taxonomy and portfolio analysis, Physical Review E, 68 (2003), pp. 056110.

[38] Tumminello, M., F. Lillo and R. N. Mantegna, Correlation, hierarchies, and networks in financial markets, Journal of Economic Behavior \& Organization, 75 (2010), pp. 40-58.

\section{Appendix: Data source and classification}

The data series are obtained from the Total Economy Database of the University of Gröningen, which updated the database of Angus (2003). I followed the International Monetary Fund (IMF) classification procedure as of April $2012^{7}$. This classification is not based on strict criteria, economic or otherwise, and it has evolved over time. The term "Economy" does not always refer to a territorial entity that is a state as understood by international law and practice. Some territorial entities included in this study are not states, although their statistical data are maintained by IMF on a separate and independent basis.

Advanced economies: Australia, Austria, Belgium, Canada, Cyprus, Czechoslovakia ${ }^{8}$, Denmark, Finland, France, Germany, Greece, Hong Kong9, Iceland, Ireland, Israel, Italy, Japan, Luxembourg, Malta, the Netherlands, New

\footnotetext{
${ }^{7} \mathrm{http}: / /$ www.imf.org/external/pubs/ft/weo/2012/01/pdf/text.pdf

${ }^{8}$ From 1991 onwards, economy composed of successor states of Czechoslovakia: Czech Republic and Slovakia.

${ }^{9}$ On July 1, 1997, Hong Kong was returned to the People's Republic of China and became a Special Administrative Region of China.
} 


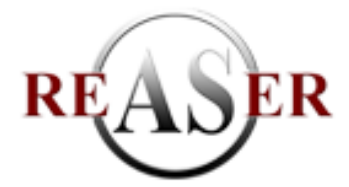

ISSN: 2247-6172;

ISSN-L: 2247-6172

Review of Applied Socio- Economic Research

(Volume 5, Issue 1/ 2013 ), pp. 189

URL: http://www.reaser.eu

e-mail: editors@reaser.eu

Zealand, Norway, Portugal, Singapore, South Korea, Spain, Sweden, Switzerland, Taiwan Province of China, United Kingdom and United States. Emergent market economies: Argentina, Brazil, Bulgaria, Chile, People's Republic of China, Hungary, India, Indonesia, Malaysia, Mexico, Pakistan, Peru, Philippines, Poland, Romania, South Africa, Thailand, Turkey, USSR ${ }^{10}$ and Venezuela. Developing economies: Albania, Algeria, Angola, Bahrain, Bangladesh, Bolivia, Burkina Faso, Cambodia, Cameroon, Colombia, Costa Rica, Côte d'Ivoire, Dominican Republic, DR Congo, Ecuador, Egypt, Ethiopia, Ghana, Guatemala, Iran, Iraq, Jamaica, Jordan, Kenya, Kuwait, Madagascar, Malawi, Mali, Morocco, Mozambique, Myanmar, Niger, Nigeria, Oman, Qatar, Saudi Arabia, Senegal, Sri Lanka, Sudan, Syria, Tanzania, Trinidad Tobago, Tunisia, UA Emirates, Uganda, Uruguay, Vietnam, Yemen, Yugoslavia, Zambia and Zimbabwe.

10 From 1991 onwards, economy composed of successor republics of USSR: Armenia, Azerbaijan, Belarus, Estonia, Georgia, Kazakhstan, Kyrgyzstan, Latvia, Lithuania, Moldova, Russian Federation, Tajikistan, Turkmenistan, Ukraine and Uzbekistan. 